\title{
Synthesis, Antibacterial and Antifungal Properties of Cyclohexane Tosyloxyimine Derivative
}

\author{
Shoaib $\mathbf{M}^{1,2 *}$ \\ ${ }^{1}$ Department of Microbiology, Faculty of Biology, Baku State University, Azerbaijan \\ ${ }^{2}$ Department of Parasitology and Microbiology, PMAS Arid Agriculture University \\ Rawalpindi, Pakistan
}

*Corresponding author: Muhammad Shoaib, Department of Microbiology, Faculty of Biology, Baku State University, Azerbaijan, Tel: (+99450) 4474229; Email: shoaib1676@gmail.com

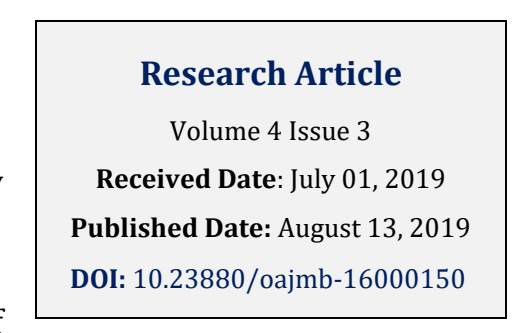

\section{Research Article}

Volume 4 Issue 3

Received Date: July 01, 2019

DOI: $10.23880 /$ oajmb-16000150

\begin{abstract}
Due to increasing antimicrobial resistance, functionally substituted cyclohexane derivatives are being explored as potential antimicrobial agents. Reaction of diethyl 4-hydroxy-6-(hyd-roxyimino)-4-methyl-2-phenylcyclohexane-1,3dicarboxylate with 4-toluenesulfonyl chloride in boiling acetone in the presence of equimolar triethylamine resulted in formation of diethyl - 4-hydroxy-4-methyl-2-phenyl-6-((tosyloxy)imino) cyclohexane-1,3-dicarboxylate. The structure of novel compound was characterized by ${ }^{1} \mathrm{H}$ and ${ }^{13} \mathrm{C}$ NMR spectra and elemental analysis was performed. Agar well diffusion assay was used to screen novel compound against Gram-positive bacteria, Gram-negative bacteria and fungi. Test compound showed better antimicrobial properties against Gram-negative bacteria as compared to Gram-positive bacteria and fungi. Acinetobacter baumannii BDU-32 was found to be most sensitive bacteria while Candida pseudotropicalis BDU MA88 was found to be most sensitive yeast.
\end{abstract}

Keywords: Acinetobacter baumannii; Agar well diffusion; Antimicrobial resistance; Cyclohexane; Tosyloxyimine derivatives

\section{Introduction}

Antimicrobial resistance is a global health problem and major obstacle in the eradication of infectious diseases. This leads to exploration of synthetic organic compounds as new antimicrobial agents with unique mode of action [1]. Functionally substituted derivatives of cyclohexane possess diverse biological properties. Anticancer activity, antioxidant activity, cytotoxic activity, anti-inflammatory activity and antimicrobial activity of different derivatives of cyclohexane has been reported in literature [2-4]. Keeping this in mind, wide range of functionally substituted cyclohexane derivatives are being explored as potential antimicrobial agents.

Diacetyl (diethoxycarbonyl) hydroxycyclohexanones act as valuable construction blocks of organic synthesis. This is due to existence of an extensive source of raw materials in the form of available 1,3- dioxocompounds (acetylacetone, ethyl acetoacetate), aliphatic and aromatic aldehydes. Furthermore, these substances have high chemical potential due to presence of oxogroups of various types [5-15]. The interaction of diethoxycarbonyl hydroxycyclohexanones with hydroxylamine corresponding oximes is studied in literature [16]. 


\section{Open Access Journal of Microbiology \& Biotechnology}

However, transformations of these oximes with use of hydroxyl group as reactionary center, has yet not been investigated. Here we report the synthesis and antimicrobial characterization of diethyl -4- hydroxy -4methyl -2- phenyl -6- ((tosyloxy)imino) cyclohexane -1, 3dicarboxylate which is formed by reaction of diethyl 4hydroxy-6- (hyd-roxyimino)- 4-methyl- 2phenylcyclohexane-1,3 -dicarboxylate with 4toluenesulfonyl chloride in boiling acetone in the presence of equimolar triethylamine.

\section{Material and Methods}

\section{Synthesis of Diethyl -4-hydroxy-4-methyl-2-phenyl- 6-((tosyloxy) imino) cyclohexane-1,3-dicarboxylate}

A solution of $5 \mathrm{mmol}$ of diethyl 4-hydroxy-6(hydroxyimino)-4-methyl-2-phenylcyclohexane-1,3-

dicarboxylate, $5 \mathrm{mmol}$ of 4-toluene-sulfonyl chloride and $5 \mathrm{mmol}$ of triethylamine in $20 \mathrm{ml}$ of acetone is boiled for 6 hours. To the resultant solution, $50 \mathrm{ml}$ of cold water is added. After 24 hours, the precipitated powder is filtered, recrystallized from ethanol.

${ }^{1} \mathrm{H}$ and ${ }^{13} \mathrm{C}$ NMR spectra recorded on a Bruker $\mathrm{AC}-300$ instrument $(300 \mathrm{MHz}$ on $1 \mathrm{H}$ and $75 \mathrm{MHz}$ nuclei at $13 \mathrm{C}$ cores) in a ( $\mathrm{CDCl}_{3}$ solution, residual signals of the solvent used as the standard. The melting points were determined on a Kofler's table. TLC monitored the purity of the resulting compounds on Silufol UV-254 plates, eluent acetone-hexane 1:2, developer-iodine vapor, UV detector.

\section{Agar Well Diffusion Assay}

Standard agar well diffusion method [17] was used to evaluate antimicrobial properties of newly synthesized derivative. Mueller-Hinton agar was used to determine in vitro antibacterial properties against four Gram-positive bacteria (Staphylococcus aureus BDU-23, Bacillus Subtilis BDU-50, Bacillus mesentericus BDU-51 and Bacillus megaterium BDU-N20) and four Gram-negative bacteria (Escherichia coli BDU-12, Klebsiella pneumoniae BDU-44, Acinetobacter baumannii BDU-32 and Pseudomonas aeruginosa BDU-49). Test compound was screened for antifungal properties against Candida tropicalis BDU LK30, Candida pelliculosa BDU KT55 and Candida pseudotropicalis BDU MA88 using sabouraud dextrose agar (SDA). All the test cultures were obtained from collection of Department of Microbiology, Baku State University. Test compound was dissolved in dimethyl sulphoxide (DMSO) and three different concentrations of test compound $(0.3 \%, 0.1 \%$ and $0.05 \%)$ were evaluated for antimicrobial activity. All the experiments were repeated three times and DMSO was used as control due to its inert nature.

\section{Results and Discussion}

\section{Synthesis of Diethyl - 4-hydroxy-4-methyl-2-phenyl- 6-((tosyloxy) imino) cyclohexane-1,3-dicarboxylate}

As shown in scheme 1, the reaction of diethyl 4hydroxy-6-(hyd-roxyimino)-4-methyl-2-

phenylcyclohexane-1,3-dicarboxylate (I) with 4toluenesulfonyl chloride (II) in boiling acetone in the presence of equimolecular triethylamine resulted in formation of diethyl - 4-hydroxy-4-methyl-2-phenyl-6((tosyloxy)imino) cyclohexane-1,3-dicarboxylate (III):
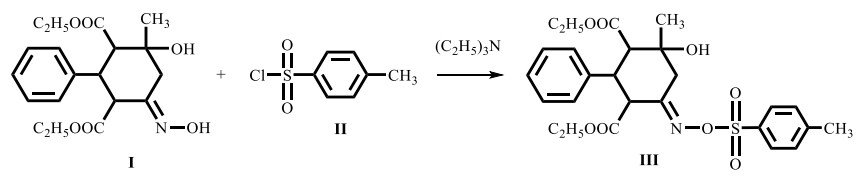

Scheme 1: Synthesis of test compound.

The catalytic role of Triethylamine (Scheme 2) act as catalyst and as a base, it chips off a proton of hydroxyl group of an oxime fragment forming an anion intermediate $(\mathrm{A})$ :

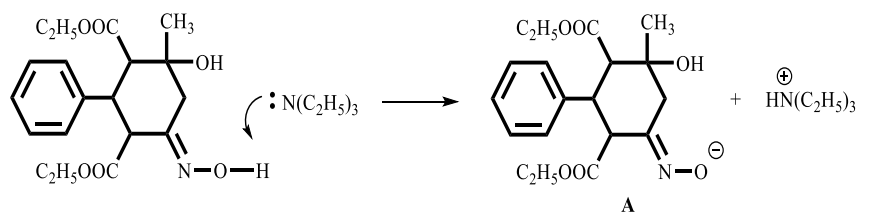

Scheme 2: Catalytic role of triethylamine.

Further this anion reacts with 4-toluenesulfonyl chloride leading to formation of a product (III) (Scheme 3):

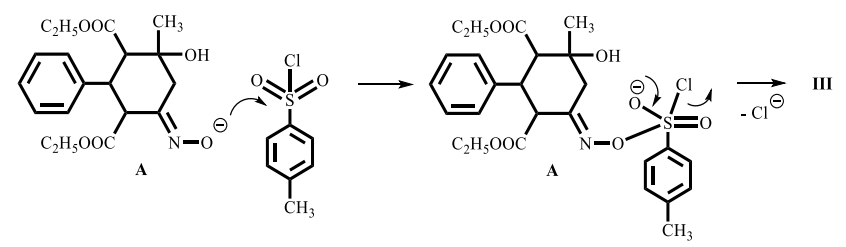

Scheme 3 


\section{Open Access Journal of Microbiology \& Biotechnology}

Diethyl - 4-hydroxy-4-methyl-2-phenyl-6-((tosyloxy) imino) cyclohexane-1,3-dicarboxylate: The compound was colorless crystals and yield was 63\%. Melting point was found to be $190^{\circ} \mathrm{C}$. ${ }^{1} \mathrm{H}$ NMR spectrum $(300 \mathrm{MHz}$, $\mathrm{CDCl}_{3}, \boldsymbol{\delta}$, ppm: 0.77 (t, $\left.3 \mathrm{H}, \mathrm{OCH}_{2} \mathrm{CH}_{3}\right) ; 0.99(\mathrm{t}, 3 \mathrm{H}$, $\left.\mathrm{OCH}_{2} \mathrm{CH}_{3}\right) ; 1.31\left(3 \mathrm{H}, \mathrm{s}, \mathrm{CH}_{3}\right) ; 2,0\left(1 \mathrm{H}, \mathrm{d}, \mathrm{CH}_{2}\right) ; 2,43(3 \mathrm{H}, \mathrm{s}$, $\left.\mathrm{CH}_{3}\right) ; 2.78\left(1 \mathrm{H}, \mathrm{d}, \mathrm{CH}_{2}\right) ; 3.51(1 \mathrm{H}, \mathrm{s}, \mathrm{OH}) ; 3.56(1 \mathrm{H}, \mathrm{d}, \mathrm{CH})$; $3.58(1 \mathrm{H}, \mathrm{d}, \mathrm{CH}) ; 3.73-4.00\left(5 \mathrm{H}, \mathrm{m}, \mathrm{OCH}_{2}, \mathrm{CH}\right) ; 7.15-7.32$ $\left(7 \mathrm{H}, \mathrm{m}, \mathrm{CH}_{\mathrm{ar}}\right), 7.80\left(2 \mathrm{H}, \mathrm{d}, \mathrm{CH}_{\mathrm{ar}}\right) \cdot{ }^{13} \mathrm{C}$ NMR spectrum $(75$ $\mathbf{M H z}, \mathbf{C D C l}_{3}, \quad \boldsymbol{\delta}$, ppm: $13.56\left(\mathrm{OCH}_{2} \mathrm{CH}_{3}\right) ; 13.83$ $\left(\mathrm{OCH}_{2} \mathrm{CH}_{3}\right) ; 28.48\left(\mathrm{CH}_{2}\right) ; 37.95(\mathrm{CH}) ; 44.93(\mathrm{CH}) ; 53.69$ $(\mathrm{CH}) ; 57.08\left(\mathrm{OCH}_{2}\right) ; 60.99\left(\mathrm{OCH}_{2}\right) ; 70.92(\mathrm{C}) ; 46.27(\mathrm{CH})$; $50.32(\mathrm{CH}) ; 63.86\left(\mathrm{OCH}_{2}\right) ; 127.84\left(\mathrm{CH}_{\mathrm{ar}}\right) ; 128.11\left(\mathrm{CH}_{\mathrm{ar}}\right)$; $128.61\left(\mathrm{CH}_{\mathrm{ar}}\right) ; 129.08\left(\mathrm{CH}_{\mathrm{ar}}\right) ; 129.46\left(\mathrm{CH}_{\mathrm{ar}}\right) ; 132.46($ $\left.\mathrm{CH}_{\mathrm{ar}}\right) ; 137.98\left(\mathrm{CH}_{\mathrm{ar}}\right) ; 145.00\left(\mathrm{CH}_{\mathrm{ar}}\right) ; 163.01(\mathrm{C}=\mathrm{N}) ; 167.50$ $\left(\mathrm{CO}_{2} \mathrm{C}_{2} \mathrm{H}_{5}\right) ; 173.64\left(\mathrm{CO}_{2} \mathrm{C}_{2} \mathrm{H}_{5}\right)$. Found, \%: C-60.51; H-6.14; $\mathrm{N}-2.88 ; \mathbf{C}_{26} \mathrm{H}_{31} \mathbf{N O}_{8} \mathbf{S}$, Calculated, \%: C-60.33; H-6.04; N2.71 (Figure 1).

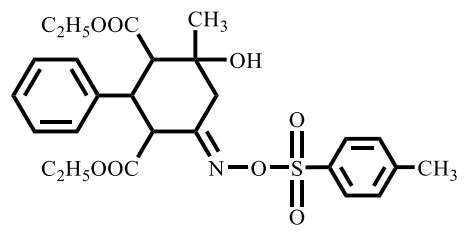

Figure 1: Structure of synthesized compound.

\section{Antimicrobial activity}

Table 1 show that test compound showed variable antimicrobial properties against different test cultures. Test compound was found to be more active against gram-negative bacteria as compared to gram-positive bacteria. At $0.3 \%$ concentration, cyclohexane derivative showed remarkable antimicrobial activity against Escherichia coli, Acinetobacter baumannii, Bacillus subtilis and Candida pseudotropicalis. Weak to moderate antibacterial activity was observed against Escherichia coli, Acinetobacter baumannii and Candida pseudotropicalis at $0.1 \%$ concentration. At $0.05 \%$ concentration, test compound was inactive against all the test cultures.

Acinetobacter baumannii was found to be most sensitive Gram-negative bacteria $(20 \mathrm{~mm}$ zone of inhibition), while Bacillus subtilis was most sensitive Gram-positive bacteria (16.7 $\mathrm{mm}$ zone of inhibition). Klebsiella pneumoniae, Pseudomonas aeruginosa, Bacillus megaterium and Bacillus mesentericus were found to be resistant against test compounds. Among the fungal cultures, Candida tropicalis and Candida pelliculosa were found to be resistant while Candida pseudotropicalis was highly sensitive. Thus, cyclohexane tosyloxyimine derivatives can act as potential antimicrobial agents in future.

\begin{tabular}{|c|c|c|c|}
\hline \multirow{2}{*}{ Test Culture } & \multicolumn{2}{|c|}{$\begin{array}{c}\text { Concentration of } \\
\text { test compound }\end{array}$} & \multirow{2}{*}{ DMSO } \\
\cline { 2 - 3 } & $0.3 \%$ & $0.1 \%$ & \\
\hline Escherichia coli & $18.3 \pm 0.3$ & $14 \pm 0.3$ & - \\
\hline Klebsiella pneumoniae & - & - & - \\
\hline Acinetobacter baumannii & $20 \pm 0.5$ & $17.3 \pm 0.6$ & - \\
\hline Pseudomonas aeruginosa & - & - & - \\
\hline Staphylococcus aureus & $14.7 \pm 0.4$ & - & - \\
\hline Bacillus subtilis & $16.7 \pm 0.9$ & - & - \\
\hline Bacillus megaterium & - & - & - \\
\hline Bacillus mesentericus & - & - & - \\
\hline Candida tropicalis & - & - & - \\
\hline Candida pelliculosa & - & - & - \\
\hline Candida pseudotropicalis & $20.7 \pm 0.3$ & $14.7 \pm 0$. & - \\
\hline
\end{tabular}

$(-)$ : Inactivity

Table 1: Average diameter of inhibition zone in $\mathrm{mm}$.

\section{References}

1. Shoaib M, Ganbarov G Kh (2019) Functionally Substituted Chemical Organic Compounds: Potential Antimicrobial Substances. J Microbiol Biotechnol 4(1): 000136.

2. Shoaib M, Israyilova AA, Ganbarov K (2019) Cyclohexane and its functionally substituted derivatives: important class of organic compounds with potential antimicrobial activities. JMBFS 9(1).

3. Song L, Kang H, Liu D, Dai Z, He J Wang, et al. (2015) Dimedone Derivative $\{2$-[(4-Hydroxy-phenylamino)methylene]-5,5-dimethyl-cyclohexane-1,3-dione\} Plays an Important Role in Breast Cancer Treatment. Tropical Journal of Pharmaceutical Research 14(9): 1719-1722.

4. Flefel EM, Sayed HH, Hashem AI, Shalaby EA, ElSofany W, et al. (2014) Pharmacological evaluation of some novel synthesized compounds derived from spiro(cyclohexane-1,2'-thiazolidines). Medicinal Chemistry Research 23(5): 2515-2527.

5. Ismiev AI, Magerramov AM, Sukach VA, Vovk MV (2016) Zh Org Farm Khim 14(4): 16.

6. Krivenko AP, Kozlova EA, Grigor`ev (2003) Regioselective Ethanolamination and Ketalization of 


\section{Open Access Journal of Microbiology \& Biotechnology}

3-Ph-2,4-diacetyl(diethoxycarbonyl)-5-hydroxy-5methylcyclohexanones. Molecules 8(2): 251-255.

7. Poplevina NV, Kuznetsova AA, Krivenko AP (2010) Synthesis and structure of substituted triazoloquinazolines. Chem Heterocycl Compd 46(9): 1148-1150.

8. Dyachenko VD, Sukach SM (2012) Synthesis of 1Hpyrazolo[3,4-c]isoquinolin-1-ones by the condensation of cyclohexanone derivatives with 3amino-1-phenyl-1H-pyrazol-5(4H)-one. Russ J Gen Chem 82(2): 305-309.

9. Ismiyev AI, Maharramov AM, Aliyeva RA, Askerov RK, Mahmudov KT, et al. (2013) Syntheses and some features of five new cyclohexane-1,3-dicarboxylates with multiple stereogenic centers. Journal of molecular structure 1032: 83-87.

10. Magerramov AM, Ismiev AI, Kadyrova NA, Gadzhieva KE, Askerov RK, et al. (2013) Crystal structure of diethyl- 1- isobutyl- 9- hydroxy- 9- methyl- 7- phenyl1, 4- diazaspiro [4,5] decane - 6, 8 - dicarboxylate $\mathrm{C}_{25} \mathrm{H}_{38} \mathrm{~N}_{2} \mathrm{O}_{5}$. Journal of Structural Chemistry 54(6): 1137-1139.

11. Hote BS, Lokhande PD (2014) Novel and Efficient Synthesis of 4-Indazolyl-1,3,4-trisubstituted Pyrazole Derivatives. Synth Commun 44(10): 1492-1500.

12. Dyachenko VD, Karpov EN (2014) Synthesis of functionalized alkyl-substituted cyclohexanones, pyridines, and 2,3,5,6,7,8-hexahydroisoquinolines by condensation of aliphatic aldehydes with $\mathrm{CH}$ acids. Russ J Org Chem 50(12): 1787-1796.

13. Dyachenko VD, Sukach SM, Dyachenko AD (2015) Synthesis of partially hydrogenated isoquinoline derivatives by condensation of 2,4-diacetyl-3aryl(hetaryl)-5-hydroxy-5-methylcyclohexanones with malononitrile and its dimer and a study of their alkylation. Chem Heterocyc Comp 51(1): 51-55.

14. Sukach SM, Dyachenko VD (2015) Multicomponent synthesis of 3-(alkylsulfanyl)-8-aryl(hetaryl)-7acetyl-6-hydroxy-1,6-dimethyl-5,6,7,8-

tetrahydroisoquinoline-4-carbonitriles. Russ J Org Chem 51(7): 1020-1025.

15. Maharramov AM, Ismiyev AI, Allahverdiyev MA, Maleev AV, Potekhin KA (2016) Crystal structure of phenylhydrazine with diacetyl substituted ketol of the cyclohexane series. Journal of Structural Chemistry 57(4): 764-770.

16. Gein VL, Nosova NV, Potemkin KD, Aliev ZG, Krivenko AP (2005) Synthesis and Structure of Diisopropyl 6Hydroxy-6-methyl-4-oxocyclohexane-1,3-

dicarboxylates and Their Reactions with Nucleophilic Reagents. Russ J Org Chem 41(7): 1016-1022.

17. Balouiri M, Sadiki M, Ibnsouda SK (2016) Methods for in vitro evaluating antimicrobial activity: A Review. Journal of Pharmaceutical Analysis 6(2): 71-79. 